\title{
Cisco Packet Tracer Simulation as Effective Pedagogy in Computer Networking Course
}

\author{
https://doi.org/10.3991/ijim.v13i10.11283
}

\author{
Nazre bin Abdul Rashid ${ }^{(凶)}$, Md. Zahar bin Othman, \\ Rasyidi bin Johan, Salman Firdaus bin Hj. Sidek \\ Universiti Pendidikan Sultan Idris, Perak, Malaysia \\ nazre@fskik.upsi.edu.my
}

\begin{abstract}
The Computer Networking course commonly taught in mixed mode involving lecture and practical session whereas beside face-to-face theory session, students need to experience hands-on activities in order to appreciate the technology and contents. Nevertheless, the abstraction in Computer Networking course such as the complexity in TCP/IP network layering, the connection and configuration of client and server's framework, differences in static and dynamic IP address configuration had imposed a great challenge for students to understand and grab the main concept of computer networking technology. As such, an approach of using computer network simulation and visualization tool in teaching and learning Computer Networking course is seen beneficial for lecturers and students. In this research, computer network simulation software of Cisco Packet Tracer was utilized in Computer Networking (MTN3023) course. Students $(\mathrm{N}=55)$ were exposed to Cisco Packet Tracer on which they developed Wide Area Network (WAN) that consists of configuration activities of Personal Computer (PC), servers and switches according to Cisco standard. Subsequently, student's feedback and their insight on the effectiveness of Cisco packet Tracer in learning computer networking were probed using questionnaire. All the feedbacks were investigate statistically using SPSS 16.0. From the analysis, the descriptive results shown that all students were agreed ( $\mathrm{N}=32$ : Strongly Agree; $\mathrm{N}=23$ : Agree) that Cisco Packet Tracer had successfully help them to understand several key concepts of computer networking and at the same quash some abstractions they faced in the course. In a nutshell, Cisco Packet Tracer as a simulation and visualization tool had been proven to be an effective software in supporting the teaching and learning of Computer Networking course.
\end{abstract}

Keywords-Computer Networking, Cisco Packet Tracer, simulation

\section{$1 \quad$ Introduction}

On the basis of the $11^{\text {th }}$ Malaysia Plan for a year 2016 to 2020, the Malaysian Public Sectors ICT Strategic Planning had drawn infinite Computer Network connections as a vital infrastructure and framework to help drive the nation economies in achieving its sustainability (MAMPU, 2016). On top of that, the significant and relevancy of Computer Networking based course in Malaysia Higher Education setting is ever- 
essential as it had been included as Body of Knowledge in all Computer Science, Software Engineering, Information Technology and Information System domains (Malaysian Qualifications Agency (MQA), 2015). Thus, the quality of teaching and learning of Computer Network course in higher education is prominent as to nurture graduates who are subject-matter competent and qualified especially when corresponded to the industrial standard.

As Computer Networking course is commonly considered as a technical subject, the teaching and learning process is always delivered in mixed mode approach involving lecture and practical session. As a result, hands-on activities are vital to be executed hand in hand with the face-to-face theory session. The combination of the two would path a way for the students to appreciate the networking technology and its contents (The Joint Task Force on ACM Computing Curricula \& Society, 2013).

In Universiti Pendidikan Sultan Idris the Computer Networking course for undergraduates (Course code: MTN3023) is taught by using internet as an example. As a result, the TCP/IP network protocols and services are forming the core content of the course. At the same time the course is being taught using the top-down approach which covered on the top layer of application layer first, then to the second transport layer, network layer and down to last layer of the data-link layer (Kurose \& Ross, 2017).

As such, in a TCP/IP network, the interconnecting layers either being looked in top down or down to top approach had been a challenge to students to comprehend due to its abstraction encompassing the protocols, services and activities among the layers. On top of that, challenges also faced by the students in grabbing the concept of the interconnected layers in actual network configuration either in the Local Area Network (LAN) or Wide Area Network (WAN) setting (Chang, 2004).

The usage of the network simulation software is essential to ease the abstraction of Computer Networking course which had been explain by Chang (2004). In this research, the impact and effectiveness of network simulator in teaching and learning of computer networking would be examined. The network simulator chosen which is Cisco Packet Tracer would be adopted mainly in a lab session.

\section{Challenges in teaching Computer Networking course}

According to Chang (2004), most lecturers had a concerned that the teaching of Computer Networking course is getting tougher and challenging based on the different background of the registered students. Chang (2004) had stated the main challenges were as follows:

1. difficult to give one teaching approach to all even among students with comparative instructive backgrounds,

2. the standards basic terms in Computer Networking are naturally extremely intricate.

3. devices and infrastructure arrangement for hands-on laboratory in Computer Networking is always being set in advance compared to Computer Programming and Computer Architecture courses. 
The usage of network simulation to facilitate teaching and learning process in the Computer Networking course seems inevitable based on all the arguments by Chang (2004) above. Furthermore, in order to adopt and use the real Cisco equipment are costly and need for some sort of know-how to handle them. Hence, by using the simulations, lecturer and students could experience the Cisco hardware without the burden of buying.

\section{$3 \quad$ Research Objectives}

The main objectives that need to be fulfilled throughout the research is divided into three which are delineated below:

1. To examine the impact of Cisco Packet Tracer as simulation in practical session of the Computer Networking course.

2. To analyse students understanding of TCP/IP network based on network that develop and configured using Cisco Packet Tracer.

3. To investigate students' acceptance and the effectiveness of Cisco Packet Tracer in teaching and learning of Computer Networking course.

\section{$4 \quad$ Research Importance and Limitation}

The research given a decent assessment on the impact and effectiveness of Cisco Packet Tracer utilization in Computer Networking course. Also, the research would exhibit that by using Cisco Packet Tracer, students would have a chance to build their own pre-defined and customise computer networks as well as setting all its necessary configurations. Beside the hardware base configuration, students would also allow to see how the packet transmitted around the built network. Ultimately, the research outcomes could be taken as a strong evidence to encourage more lecturer to adopt Cisco Packet Tracer tool as their teaching aid.

As for the limitation, the research is conducted only in Universiti Pendidikan Sultan Idris (UPSI) and focusing on the undergraduates registered for Computer Networking (Course Code: MTN3023) in semester two of a year session 2016/2017 (Session code: A162) as the participants. Also, the Cisco Packet Tracer is the only network simulation being used throughout the research.

\section{Overview of Computer Networking simulation}

Anisetti et al. (2007) had compared several nnetwork simulators that are available in the market and could be adopted to delivers network visualization to students. The simulator are namely TeleLab, Mimic, VirtuoPro, MLN, OVL and Packet Tracer. The authors agreed that network simulator is paramount in giving the practical experience to students and along the way the basis comprehension of computer networking principles among students could be heightened. Moreover, the popularity of Virtual 
Machine (VM) had escalated the chances of using network simulators that enable students to create a simple yet creative network which can develop their practical skills mainly in computer network troubleshooting efforts. Recently, many intuitions had been using simulator as the tools are cost-effective yet permitting the learning process to be executed without the limitation of time and space (Nawaz, 2013).

According to Sarkar (2005), network simulator is essential because most students found the computer networking is a complicated subject and at times their drive to digest the content was low because of they perceive it as a dull and uninteresting subject. As such, Sarkar (2005) in his research developed a simulator called LANDesigner to tackle this issue. LAN-Designer had been used in Auckland University of Technology. Based on the students' comment the development and adoption of LANDesigner was effective.

On the other hand, network simulators also being blended with relevant exercises based on multiple developed methodologies. The network simulators plus exercise were given to students in different set of learning process to enhance their understanding on the computer networking configuration details. In some cases, the simulators and exercises were developed in a local native language and used to aid students to prepare for a Cisco Certified Network Associate (CCNA) courses (Kainz et al., 2016).

Finally, network simulation is best utilized to enhance "experiential" learning among students in the learning of Computer Networking course. Beside lecture and lab sessions, students would use simulation to understand the abstraction of computer network which include the connection among the layers. The simulation which used personalized computer gave students a chance to verify all the knowledge that they acquire form the books. At the mean time most of the important network protocols such as Internet Protocol (IP), Address Resolution Protocol (ARP), Domain Name System (DNS) and Transmission Control Protocol (TCP) could be practiced by students when using the simulation in their learning process (Chang, 2004).

\subsection{Cisco Packet Tracer}

According to Liangxu et al. (2013) and Herbert and Wigley (2015), Cisco Packet Tracer is a powerful visualization and simulation computer network software tool that could be accessed for free by students who registered in a Cisco Network Academy program. On the other hand, the tool could still be used by those outside the academy limited to educational purposes only.

It had been reported by Herbert and Wigley (2015) that Cisco Packet Tracer has a sheer advantage to be adopted in Computer Networking course based on the following reasons:

1. Makasiranondh et al. (2010) found that the introduction of Cisco Packet Tracer would save cost compared to the thousands that need to be allocated to buy the real physical Cisco equipment.

2. Packet Tracer's could enhance learning which allow learners to outwardly observe the packet development and routes through the created network 
3. Packet Tracer requires less capacity of disk space and secondary memory since it is just emulating the real environment where no real packet transmission is happening (Gil et al. 2015).

4. according to Frezzo et al. (2010), no harm or interruption would strike the real network on the grounds that Packet Tracer does not really utilize any physical network gadgets.

5. as mentioned by Javid (2014) Packet Tracer additionally gives the tools to enable teachers to set appraisals, assignments, tests and exercises. Likewise, it is conceivable to utilize Packet Tracer for group tasks.

In conclusion, the research consequences of Javid (2014) and Janitor et al. (2010) were at agreement that Cisco Packet Tracer is a suitable supporting tool to be used in teaching and learning of Computer Networking course yet it should not be looked as a full alternative to the real network devices (Herbert \& Wigley, 2015).

\section{Utilization of Cisco Packet Tracer in UPSI}

The computer network simulation utilized is consisting of the DHCP, DNS and HTTP servers along with switches and Personal Computer or Laptops. Students will use Cisco Packet Tracer features to configure each of the required devices in a single network domain using a specific classful IPv4 addressing. Below are some of the explanation of several key hardware used in the simulation:

Switch: A network switch is a computer networking peripheral that joins network nodes together on the same network domain. As such, switch is acting as a common channel for the packet transmission among nodes in the same network. Switch is a simple device as no detail's configuration need to be done onto it. Switch is plug-nplay and in the simulation, students are required to utilise two switches as to manifest a modest client-server network environment.

DHCP Server: The DHCP (dynamic host configuration protocol) server is a computer network device that runs the DHCP protocols. This server will allocate internet protocol (IP) address and other related parameters automatically to any devices who requested for it prior joining the network. In this case, the devices will be recognized as a dynamic IP node. In the simulation, students is required to configure one (1) Personal Computer (PC) as a dynamic PC to allow the communication between the PC and the DHCP server. Another PC which is not configure as dynamic will be called static PC where its IP address will be configured manually by the network administrator.

DNS Server: DNS (domain name server) is a server which is responsible to translate server's name to IP address and vice-versa. As such, it permits the browsing of website by nodes using the Uniform Resource Locator (URL) instead of IP address which is always convenience to end-users (human). In the simulation, students will configure the DNS server to allow the PCs to browse the HTTP server by URL.

HTTP Server: The main function of HTTP (Hypertext Transfer Protocol) server is to store the web pages which is browsable by clients. Therefore, the server also known as a Web server. The HTTP server web pages could be opened by the clients using 
either IP address or URL where the latter is more convenience to be used (with the help of DNS server). In the simulation, students will configure the HTTP server by activating the necessary services. They also need to customise the default Hypertext Markup Language (HTML) to suits their network configuration context.

Personal Computer/Laptop: The personal computer or laptop were utilized as basic nodes in the network. These devices are important as students would learn on the IP address configuration statically or dynamically. They would also be used for connection testing such as using PING command for pc-to-pc or pc-to-server communication.

The simulation big picture consisting all the devices that mentioned above is depicted by Figure 1 below:

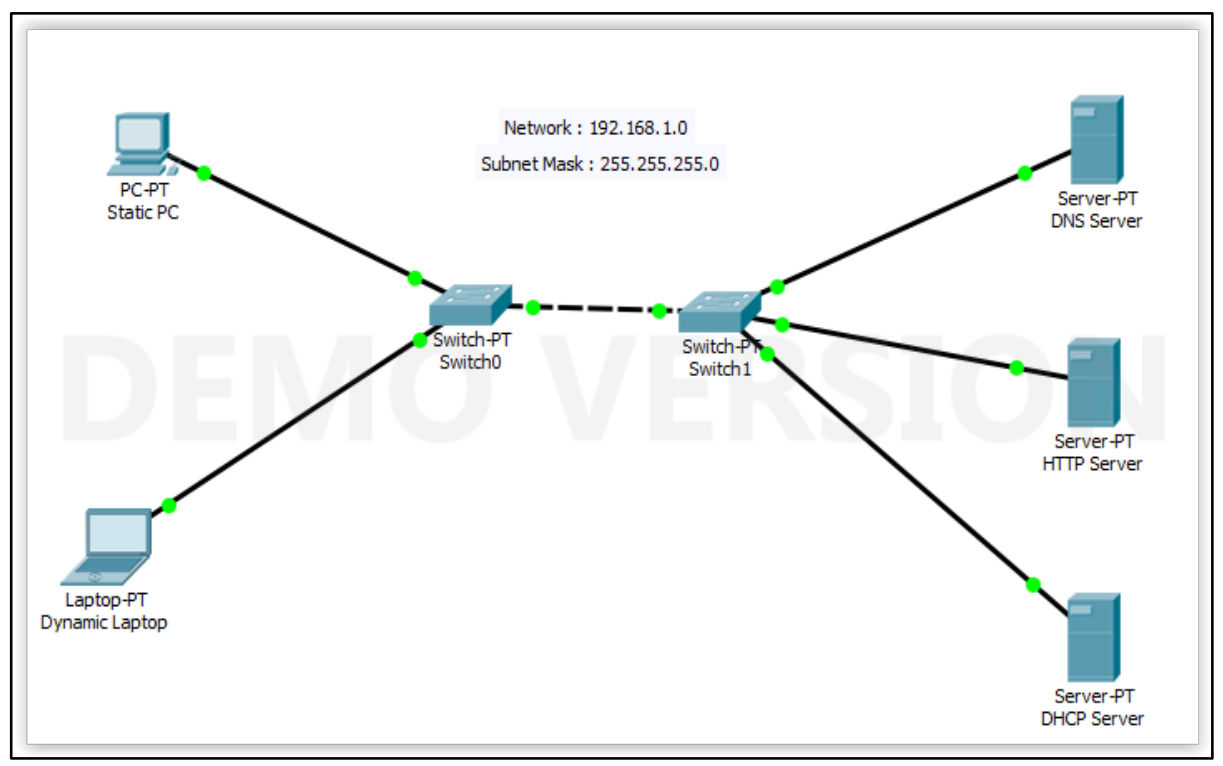

Fig. 1. Computer network simulation using Cisco Packet Tracer.

\section{$7 \quad$ Results and Discussion}

In this section the students' perception and feedback on TCP/IP Network particularly on the layering concept is shown. Figure 2 shows that majority of the students $(N=44$, $80 \%$ ) accepted the facts the layering concept is hard to conceptualize and imagined. This is concurred to some of the previous research findings for instance by Chang (2004).

Nevertheless, after being exposed to Cisco packet Tracer, students gained valuable insight and feel more comfortable in designing and configuring their own Local Area Network (LAN) without worries on the layering abstraction. This situation had been shown in Figure 3 where all students are confidence in creating LAN to the extent that 19 are very confident in their response. 


\section{The interconnection of TCPIIP layers is hard to be conceptualizelimagined}



Fig. 2. Students' perception on Computer Network TCP/IP layering abstraction

Student is confident to configure a real Local Area Network after using CISCO Packet Tracer

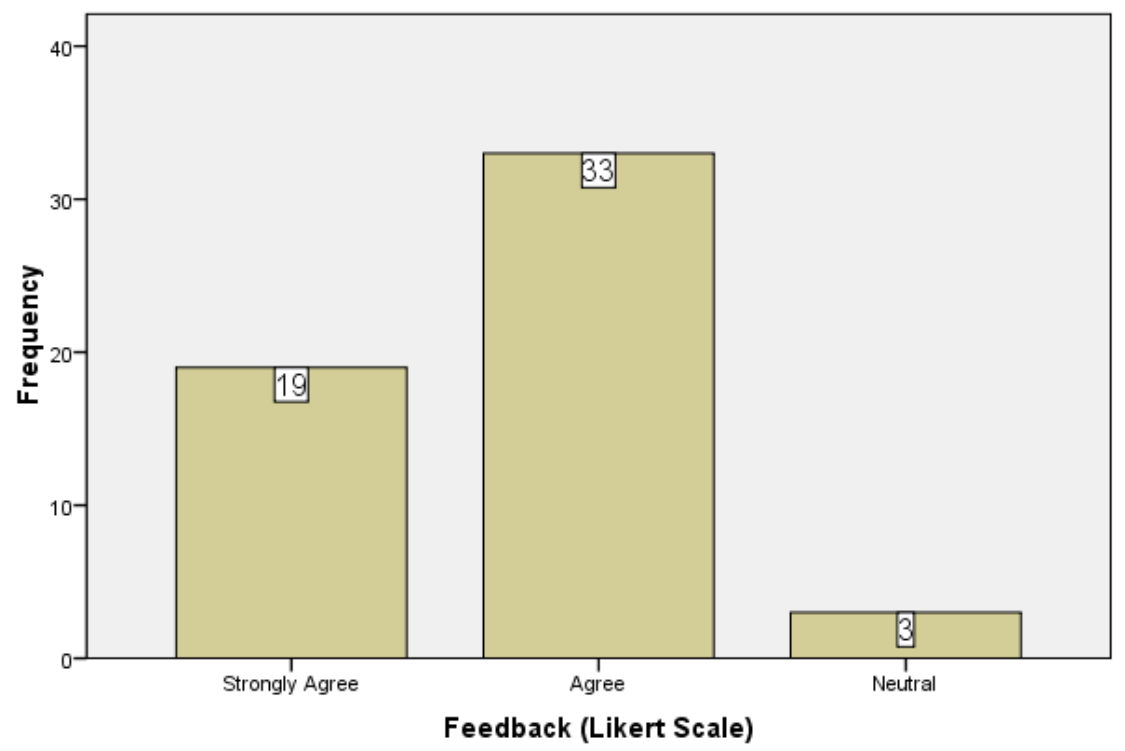

Fig. 3. Students' confident in configuring LAN after exposed to Cisco Packet Tracer 
Students' critical assessment on Cisco packet Tracer is shown in this section. Figure 4 shows that all students are able to simulate the LAN environment which compromising several key hardware such personal computer, laptop, servers and switches as being outlined in the previous section. They also manage to specify the best and correct connectors (wires) to connect every device in the LAN. In the survey 35 participants given the response of "Strongly Agree" to the questions which indicated their appreciations on the utilization of Cisco Packet Tracer in the MTN3023 course.

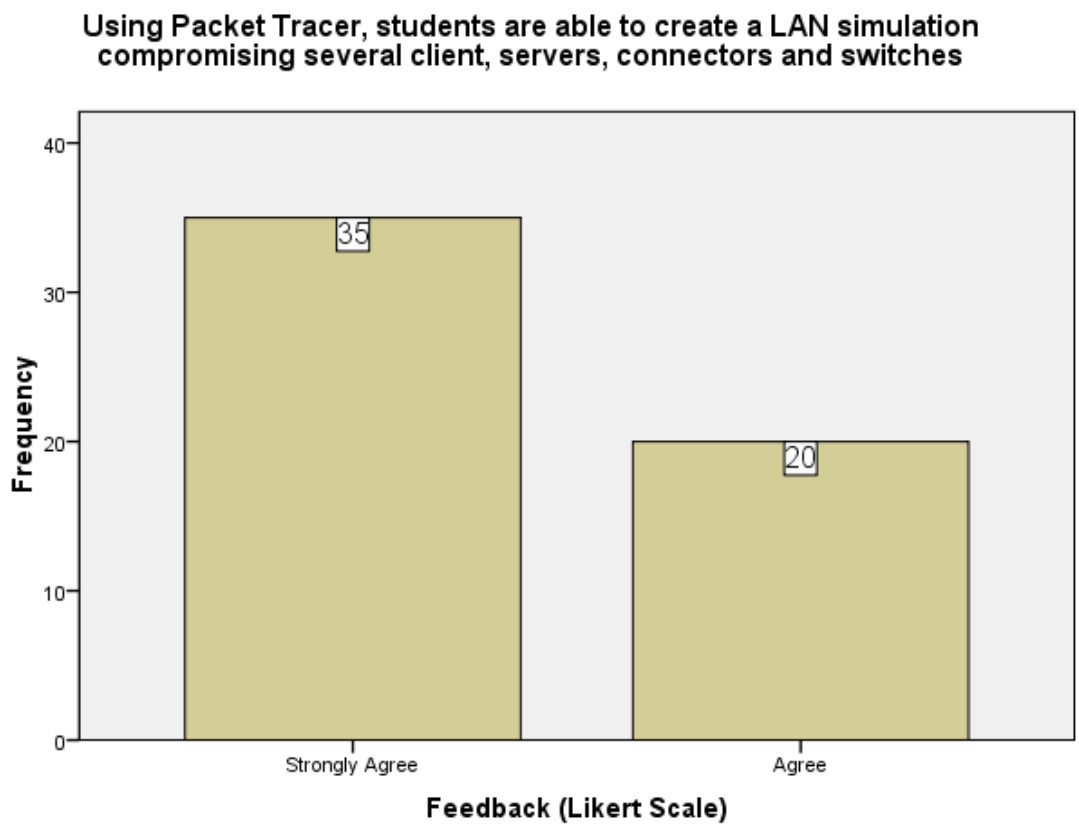

Fig. 4. Students' ability to create LAN using Cisco packet Tracer

In LAN configuration and development, students are required to plan the network and one of the important parts is to manage the network IP class. Using Cisco Packet Tracer, students were exposed with the configuration of IP address for each node. By that they are bound to know the class of IP and its corresponding network address, subnet mask address and broadcast address. Figure 5 shows that 28 participants are "Strongly Agree" and 24 participants are "Agree" to the fact that those information are easily specified and understood by using Cisco packet Tracer. Students also got experience in configuring each nodes IP address using the simulation either by static or dynamic configuration. Figure 6 shows 54 participants are in the group of "Strongly Agree" and "Agree" combined in term of their ability to correctly configured IP address for each node in the simulation. Meanwhile Figure 7 shows all students are in agreement that Cisco Packet Tracer gave them chances to configure IP address in both static and dynamic conditions. 
Using CISCO Packet Tracer, students are able to specify the Class of IP, The Subnet mask address and the broadcast IP address for the LAN



Fig. 5. Students' ability to specify IP address information using Cisco packet Tracer

Using CISCO Packet Tracer, students are able to configure the IP address for each nodes in the LAN

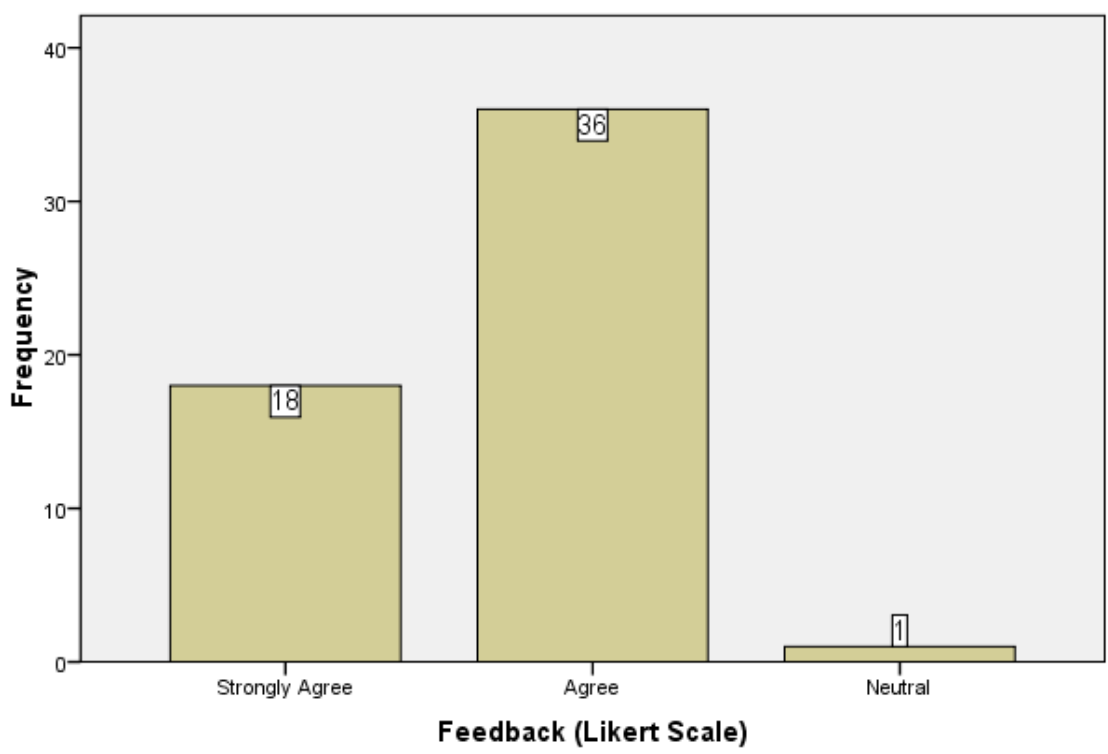

Fig. 6. Students' ability to configure IP Address for each node in Cisco Packet Tracer 
Using CISCO Packet Tracer, students are able to configure PC/Clients in Static and Dynamic IP

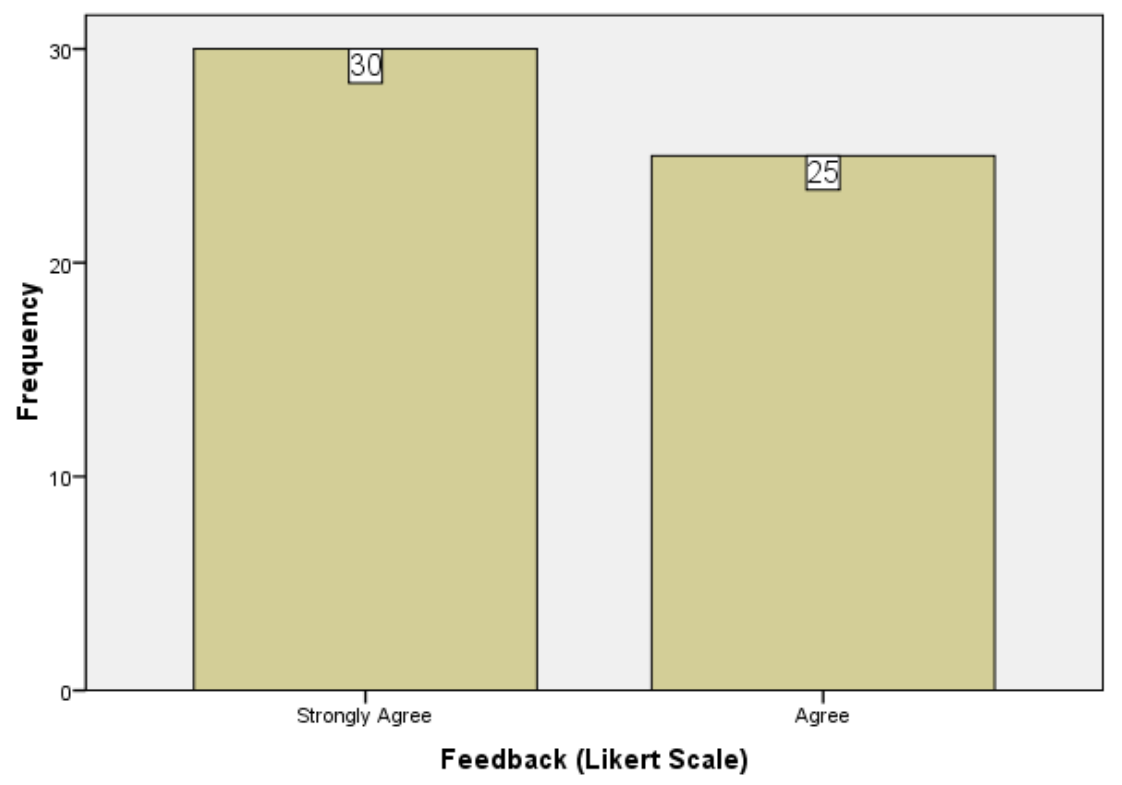

Fig. 7. Students' ability to configure Static and Dynamic IP address in Cisco Packet Tracer

One of the main set-ups in computer networking is client and server architecture. By that, it is vital for student to grab the concept on this architecture. Figure 8 gave a strong indication on the effectiveness of Cisco Packet Tracer in simulating the architecture and exhibiting the environment to students. Here, students' overview on the functionality of servers are shown which depicted all students to concord (27 Strongly Agree and 26 Agree) on Cisco Packet Tracer capability to simulate the server connection and communication to clients 




Fig. 8. Students' overview on servers' functionality using Cisco Packet Tracer

Finally, students' overall feedback on the utilization of Cisco packet Tracer as simulating tool in teaching and learning of MTN3023 course is depicted by Figure 9. It is clearly shown that all students (34 Strongly Agree and 21 Agree) that Cisco Packet Tracer had help them in their understandings on how computer networks work. Their feedback is truly based on the potentiality of Cisco Packet Tracer in simulating key computer network concept as being explained and shown in the related paragraphs and figures. 
Overall, CISCO Packet Tracer helps in my understanding on how the TCPIIP or LAN network works



Fig. 9. Students' overall feedback on Cisco Packet Tracer

\section{Conclusion}

The deployment of Cisco Packet Tracer in the course and students' feedback is reported based on the research objectives. Each objective and the explanation on its accomplishment are as follows:

Objective 1: To examine the impact of Cisco Packet Tracer as simulation in practical session of the Computer Networking course

The Cisco Packet Tracer had been deployed and utilize in the MTN3023 as a simulation tool. Based on the participants" feedback which exhibited in the Results and Discussion section, they had gained experience and confidence to configure Local Area Network (LAN) after being exposed to Cisco Packet Tracer. As such, the Cisco Packet Tracer had been discovered of putting a positive impact on students' understanding and tendency towards the course.

Objective 2: To analyse students understanding of TCP/IP network based on network that develop and configured using Cisco Packet Tracer

Students had given a very positive and good feedback on how Cisco Packet Tracer enhanced their understanding of TCP/IP network. The simulation helps to ease the abstraction of TCP/IP layering framework which always be an obstacle in TCP/IP understanding among students. Moreover, using Cisco Packet Tracer students were able to configured basic TCP/IP settings such as IP address configuration, connections and server configuration. On top of that, students also exposed to client-server environment which could be easily simulated using Cisco Packet Tracer. By 
understanding the client-server environment alone had benefitted students in a very large view as the framework is forming a vast aspect of TCP/IP network.

Objective 3: To investigate the effectiveness of Cisco Packet Tracer in teaching and learning of Computer Networking course

One of the hardest things in computer networking teaching and learning is to simulate the real-world network without an appropriate hardware (which is costly to buy). By using Cisco packet Tracer simulation tool, the challenge had been smoothening and students had a big opportunity to simulate real world network easily and effectively. This had been proven by a feedback by students who sense that they are more confident configuring LAN after using the simulation. They also feel that their understanding on the TCP/IP network had been better than before. Moreover, the Cisco Packet Tracer allows them to configure each node (PC, Servers etc.) which give them opportunity to explore and dictate the network development with their own wisdom. Finally, based on students' overall feedback the effectiveness of Cisco Packet Tracer is ever-essential in assisting them to master the computer network course.

Overall, the Cisco Packet Tracer had been successfully deployed as a simulation tool in MTN3023 course and the students' feedback is enormous. Its help to support the practical part of the course with a minimal cost. On top of that, the simulation also seen as stepping stone for the students to go for professional Cisco certification as by using Cisco Packet Tracer they were actually virtually working with real Cisco hardware.

Moving forward the Cisco Packet Tracer should be used to support the lecture materials on which the top-down approach in computer networks teaching and learning had been employed in Universiti Pendidikan Sultan Idris. The network layer abstraction must be look into and investigated in deeper manner. Then, Cisco Packet Tracer could be used to simulate the main layer abstraction by which students' understanding on the abstraction is answered.

\section{Acknowledgement}

This research was approved and financially supported by the Research Management and Innovation Centre (RMIC), Universiti Pendidikan Sultan Idris under the university research grant of 2016-0173-109-01. We thank our colleagues and students from Computing Department, Faculty of Arts, Computing and Creative Industry who provided insight, expertise and contribution that greatly assisted the research.

\section{References}

[1] Anisetti, M., Bellandi, V., Colombo, A., Cremonini, M., Damiani, E., Frati, F., ... \& Rebeccani, D. (2007). Learning computer networking on open paravirtual laboratories. IEEE Transactions on Education, 50(4), 302-311. https://doi.org/10.1109/te. $\underline{2007.904584}$

[2] Chang, R. K. (2004, June). Teaching computer networking with the help of personal computer networks. In Proceedings of the 9th annual SIGCSE conference on Innovation and 
technology in computer science education (pp. 208-212). https://doi.org/10.1145/ 1007996.1008052

[3] Frezzo, D. C., Behrens, J. T., \& Mislevy, R. J. (2010). Design patterns for learning and assessment: Facilitating the introduction of a complex simulation-based learning environment into a community of instructors. Journal of Science Education and Technology, 19(2), 105-114. https://doi.org/10.1007/s10956-009-9192-0

[4] Gil, P., Garcia, G. J., Delgado, A., Medina, R. M., Calderon, A., \& Marti, P. (2015). Computer networks virtualization with GNS3: Evaluating a solution to optimize resources and achieve a distance learning. In Proceedings - Frontiers in Education Conference, FIE (Vol. 2015-Febru, pp. 1-4). IEEE. https://doi.org/10.1109/fie.2014.7044343

[5] Herbert, B. M., \& Wigley, G. B. (2015). The Role of Cisco Virtual Internet Routing Lab in network training environments. (Honours Thesis).

[6] Janitor, J., Jakab, F., \& Kniewald, K. (2010). Visual learning tools for teaching/learning computer networks: Cisco Networking Academy and Packet Tracer. In Networking and Services (ICNS), 2010 Sixth International Conference on (pp. 351-355). IEEE. https://doi.org/10.1109/icns.2010.55

[7] Javid, S. R. (2014). Role of Packet Tracer in learning Computer Networks. International Journal of Advanced Research in Computer and Communication Engineering, 3(5), 65086511.

[8] Kainz, O., Cymbalak, D., Lamer, J., Michalko, M., \& Jakab, F. (2016). Innovative methodology and implementation of simulation exercises to the Computer networks courses. In ICETA 2015 - 13th IEEE International Conference on Emerging eLearning Technologies and Applications, Proceedings (pp. 1-6). IEEE. https://doi.org/10.1109/ iceta.2015.7558481

[9] Kurose, J. F., \& Ross, K. W. (2017). Computer networking: a top-down approach. Pearson (7th ed., Vol. 7). Essex: Pearson Education Limited.

[10] Liangxu Sun, Jiansheng Wu, Yujun Zhang, \& Hang Yin. (2013). Comparison between physical devices and simulator software for Cisco network technology teaching. In 2013 8th International Conference on Computer Science \& Education (pp. 1357-1360). IEEE. https://doi.org/10.1109/iccse.2013.6554134

[11] Makasiranondh, W., Maj, S. P., \& Veal, D. (2010). Pedagogical evaluation of simulation tools usage in Network Technology Education. World Transactions on Engineering and Technology Education, 8(3), 321-326.

[12] Malaysian Qualifications Agency (MQA). (2015). Programme Standards: Computing. Retrieved from http://www2.mqa.gov.my/QAD/garispanduan/Computing.pdf

[13] MAMPU. (2016). The Malaysian Public Sector ICT Strategic Plan 2016-2020. Retrieved from http://www.mampu.gov.my/images/agensikerajaan/perkhidmatan/The-MalaysianPublic-Sector-ICT-Strategic-Plan-2016 2020.pdf

[14] Sarkar, N. I. (2005). LAN-Designer: A software tool to enhance learning and teaching server-based LAN design. International Journal of Information and Communication Technology Education (IJICTE), 1(2), 74-86. https://doi.org/10.4018/jicte.2005040107

[15] The Joint Task Force on Computing Curricula, (ACM), A. for C. M., \& Society, I. C. (2013). Computer Science Curricula 2013. https://doi.org/10.1145/2534860 


\section{Authors}

Mr. Nazre bin Abdul Rashid holds a PhD in Electrical Engineering by the Universiti Teknologi Mara (UiTM), Malaysia and he is currently a Senior Lecturer at the Department of Computing, Faculty of Arts, Computing and Creative Industry, Sultan Idris Education University (UPSI), Malaysia. His main area of interest is the study on human potentials focusing on the brain signals (EEG) and on ICT adoption towards teaching and learning in the higher institution domain. He is an active member of IEEE and Malaysia Board of Technologist (MBOT). nazre@,fskik.upsi.edu.my

Tn. Hj Md Zahar bin Othman is a Senior Lecturer at the Department of Computing, Faculty of Arts, Computing and Creative Industry, Sultan Idris Education University, Malaysia. He had with him 30 years' experience in teaching Computer Science courses such as Computer Networking, Computer Security, System Administration and Object-oriented programming. Devoted towards an Open-Source systems, Mr. Md Zahar had a very keen interest in Python programming and had been actively involved in promoting the language to Malaysia higher institutions and schools. zahar@,fskik.upsi.edu.my

Mr. Rasyidi bin Johan holds a Master's Degree in Information Technology by the Universiti Teknologi Mara (UiTM), Malaysia. He is currently a Lecturer a at the Department of Computing, Faculty of Arts, Computing and Creative Industry, Sultan Idris Education University, Malaysia. His research interest is mainly on on-line system development, intelligence system and multimedia digital application. Mr. Rasyidi has a great interest in Windows-based programming and had won several awards on his Automation Format Thesis (AF-Thesis) application system. rasyidi@,fskik.upsi.edu.my

Mr. Salman Firdaus bin Hj. Sidek received his Master's degree in Computer Science from UniversitiTeknologi Malaysia (UTM). He is a Lecturer a at the Department of Computing, Faculty of Arts, Computing and Creative Industry, Sultan Idris Education University, Malaysia where he thought several courses encompassing Computer Architecture and Organization, Operating System and Computer Networking. Mr. Salman is actively involved in MOOC initiative in UPSI and his MOOC system had won several awards at national level. Mr. Salman is currently pursuing his doctoral degree in Gamification. salmanfirdaus@,fskik.upsi.edu.my

Article submitted 2019-06-15. Resubmitted 2019-07-26. Final acceptance 2019-07-29. Final version published as submitted by the authors. Corrections applied 2021-01-11. 